\title{
Perfil do Ecoturismo no Rio Araguaia: uma Análise Histórica
}

\author{
Fernanda Geórgia Parrião ${ }^{1}$, Mariana Arcanjo Costa ${ }^{1}$, Patrícia Martins ${ }^{1}$, Yeda Soares de Lucena Bataus ${ }^{2}$, Otair Lourenço da \\ Silva Júnior ${ }^{3} \&$ Rafael Antônio Machado Balestra²
}

Recebido em 28/08/2020 - Aceito em 15/09/2020

1 Universidade Federal de Goiás - UFG, Instituto de Ciências Biológicas - ICB, Goiânia (GO), CEP: 74.423-020, Brasil. <fernanda.parriao@gmail.com> (Estagiárias PIBIC - RAN/ICMBio).

2 Instituto Chico Mendes de Conservação da Biodiversidade/ICMBio, Centro Nacional de Pesquisa e Conservação de Répteis e Anfíbios/RAN, Goiânia (GO), CEP:74605-090, Brasil. < rafael.balestra@icmbio.gov.b>r (Analistas Ambientais - RAN/ICMBio).

3 Pontifícia Universidade Católica de Goiás - PUC/GO, Departamento de Ciências Biológicas - DBio, CEP: 74.658-100, Brasil. <otairjr@gmail.com, (Estagiário PIBIC - RAN/ICMBio).

RESUMO - O rio Araguaia nasce na Serra dos Caiapós, entre os estados de Mato Grosso e Goiás, inserido no bioma Cerrado. Na época de estiagem, suas praias são bastante procuradas para acampar. Neste estudo foram avaliados os dados do projeto "Ordenamento do Turismo e Ecoturismo no Rio Araguaia" implementado pelo Centro Nacional de Pesquisa e Conservação de Répteis e Anfíbios na região do médio rio Araguaia, compreendendo a Área de Proteção Ambiental Meandros do Rio Araguaia, Reserva Extrativista Lago do Cedro e Parque Nacional do Araguaia. Foram desenvolvidas as seguintes etapas: 1) levantamento dos dados obtidos a partir da aplicação de questionários aos turistas sobre as formas de uso de praias e dos ambientes circundantes; 2) desenvolvimento de um banco de dados; e 3) sistematização, análises e proposições. São apresentados neste artigo os resultados da avaliação dos 11 primeiros anos de execução do projeto, contemplando 1.913 questionários aplicados, relativos ao comportamento ambiental de campistas em praias do rio Araguaia, de um total de 4.697 acampamentos monitorados entre os anos de 2003 e 2012. Observou-se que os responsáveis pelos acampamentos, em sua maioria, são procedentes do estado de Goiás (89,70\%), coadunando com o hábito goiano de acampar no Araguaia. De 1.746 (91,27\%) questionários que contêm informações sobre o destino do lixo, verificou-se que $61,74 \%$ dos acampamentos optaram por atitudes positivas, como deixar o lixo na cidade mais próxima, enterrar às margens do rio somente o lixo orgânico, ou deixar para a prefeitura ou associação de barqueiros coletar. De $1.696(88,66 \%)$ questionários que contêm informações sobre o material usado na estrutura dos acampamentos, observou-se que o uso da madeira nativa ocorreu de forma pouco expressiva $(5,60 \%)$, sendo que a utilização de materiais adequados atingiu $81,66 \%$. Este estudo indica que o projeto avaliado resultou em melhoria na relação da atividade turística e conservação dos recursos naturais do médio Araguaia, devendo suas ações e atividades serem incentivadas, continuadas e aprimoradas.

Palavras-chave: Acampamento; conservação; lixo; resíduos sólidos; natureza.

\section{Ecotourism on the Araguaia River: a Historical Analysis}

ABSTRACT - The Araguaia river rises in the Serra dos Caiapós between the states of Mato Grosso and Goiás, inserted in the Cerrado biome. In the dry season, its beaches are very popular for camping. In this study, the data from the project "Ordering of Tourism and Ecotourism in the Araguaia River", implemented by the National Center for Research and Conservation of Reptiles and Amphibians in the region of the middle Araguaia River, comprising the Environmental Protection Area Meandros do rio Araguaia, Lago do Cedro Extractive Reserve and Araguaia National Park. The following steps were carried out: 1) survey of data obtained from the application of questionnaires to tourists on the ways of using beaches and the surrounding environments; 2) development of a database; and, 3) systematization, analysis and propositions. The results of the detailed evaluation of the first 11 years of the project's execution are presented in this article, comprising 1913 questionnaires applied regarding the environmental behavior of campers on the beaches of the Araguaia river, contemplating a total of 4697 campsites monitored between 2003 and 2012. It was observed that those responsible for the camps, in their majority, come from the state of Goiás (89.70\%), in line with Goiás state people habit of camping in Araguaia. 
Of $1746(91.27 \%)$ questionnaires containing information about the destination of the garbage, it was found that $61.74 \%$ of the camps opted for positive attitudes, such as leaving the garbage in the nearest city, burying only the organic garbage in the river banks, or leave it to the city hall or boatmen's association to collect. Of $1696(88.66 \%)$ questionnaires that contain information about the material used in the structure of the camps, it was observed that the use of native wood occurred in a small way $(5.60 \%)$, and the use of suitable materials reached $81.66 \%$. This study indicates that the evaluated project resulted in an improvement in the relationship between tourism and conservation of natural resources in the middle Araguaia river, and its actions and activities should be encouraged, continuous and improved.

Keywords: Camping; conservation; trash; solid waste; nature.

\section{Perfil del Ecoturismo en el Río Araguaia: un Análisis Histórico}

RESUMEN - El río Araguaia nace en la Serra dos Caiapós, entre los estados de Mato Grosso y Goiás, insertado en el bioma Cerrado. En la estación seca, sus playas son muy populares para acampar. En este estudio, los datos del proyecto "Ordenamiento de Turismo y Ecoturismo en el Río Araguaia" implementado por el Centro Nacional de Investigación y Conservación de Reptiles y Anfibios en la región del medio río Araguaia, que comprende la Área de Protección Ambiental Meandros do rio Araguaia, Reserva Extractiva Lago do Cedro y el Parque Nacional do Araguaia. Se llevaron a cabo los siguientes pasos: 1) encuesta de datos obtenidos de la aplicación de cuestionarios a turistas sobre las formas de usar las playas y los entornos circundantes; 2) desarrollo de una base de datos; y, 3) sistematización, análisis y propuestas. En este artículo se presentan los resultados de la evaluación detallada de los primeros 11 años de ejecución del proyecto, que comprende 1913 cuestionarios aplicados sobre el comportamiento ambiental de los campistas en las playas del río Araguaia, de un total de 4697 campings monitoreados entre 2003 y 2012. Se observó que los responsables de los campamentos, en su mayoría, provienen del estado de Goiás (89.70\%), en línea con el costumbre de acampar de los povos del Goiás no río Araguaia. De 1746 (91.27\%) cuestionarios que contienen información sobre el destino de la basura, se encontró que el 61.74\% de los campamentos optaron por actitudes positivas, como dejar la basura en la ciudad más cercana, enterrar solo la basura orgánica en las orillas del río, o dejarlo en el ayuntamiento o la asociación de barqueros para recoger. De 1696 $(88.66 \%)$ cuestionarios que contienen información sobre el material utilizado en la estructura de los campamentos, se observó que el uso de madera nativa se produjo de manera pequeña (5.60\%), y el uso de materiales adecuados alcanzó $81,66 \%$. Este estudio indica que el proyecto evaluado resultó en una mejora en la relación entre el turismo y la conservación de los recursos naturales en el médio río Araguaia, y sus acciones y actividades deberían ser alentadas, continuas y mejoradas.

Palabras clave: Campamento; conservación; basura; residuos sólidos; naturaleza.

\section{Introdução}

O ecoturismo caracteriza-se pela modalidade turística que utiliza, predominantemente, recursos naturais como forma de atração, contemplação e lazer, os quais se constituem como matériasprimas para o desenvolvimento do ecoturismo. Trata-se de um movimento turístico recente, que tem obtido relevâncias tanto econômicas, sociais, culturais quanto ambientais, pois, como abordam Serrano e Luchiari (2005), mesmo antes das definições dos termos e da comercialização de atividades relacionadas ao ecoturismo, já se destacavam algumas viagens de lazer à natureza.
A maior importância do ecoturismo na sociedade não está apenas baseada na variável econômica, mas, principalmente, em seu potencial educativo e de conservação da natureza, advindos das experiências e sensações vivenciadas em meio à natureza. $\mathrm{O}$ caráter educativo do ecoturismo baseia-se no fato de que essa atividade, comprometida com a conservação da natureza, prevê o seu desenvolvimento a partir da participação responsável dos ecoturistas em ambientes de elevada importância tanto para essa atividade quanto para a humanidade. 
Para Mendonça (2005), as experiências ecoturísticas possuem elevado potencial para a interiorização de princípios da educação ambiental, pois "[...] promovem o aprimoramento das relações dos indivíduos, consigo mesmos e auxiliam a tornar conscientes as relações que as pessoas têm umas com as outras e com o meio natural".

Presume-se, assim, que a forma mais adequada de desenvolver esse processo educativo no ecoturismo seja por meio da incorporação de modalidades de educação ambiental às práticas a ela associadas.

A educação ambiental constitui uma possibilidade de conter os impactos negativos ocasionados pelo ecoturismo, pois possui como objetivo a implementação de um processo sistemático de educação que induz o indivíduo (educando) a uma ação-reflexão-ação, com o objetivo de compreender as consequências ocasionadas por seus comportamentos e por suas atitudes perante a natureza, sendo que o ato de refletir sobre uma dada situação possivelmente levará o indivíduo a agir em prol de benefícios que possa oferecer à conservação da natureza.

O rio Araguaia nasce no estado de Goiás, nas formações elevadas existentes no Parque Nacional das Emas, divisa dos estados de Goiás e Mato Grosso. Pertence à bacia Tocantins-Araguaia, tendo uma área total de, aproximadamente, $379.836 \mathrm{~km}^{2}$ (Latrubesse, 2002). Está inserido na região biogeográfica dos Cerrados, formado por diferentes fitofisionomias (Ratter et al., 1997; Barbosa, 2008). Seus meandros favorecem a diversidade biológica, contribuindo consideravelmente para tornar o cerrado brasileiro um dos principais hotspots de biodiversidade mundiais (Myers et al., 2000), com cerca de 10 mil espécies só de vegetais, conectando o bioma Cerrado aos biomas do Pantanal e Amazônico (Borges, 2010).

Durante o período deste estudo, o turismo na região do rio Araguaia cresceu intensamente, proporcionando aumento de receita para os municípios de Aragarças, Aruanã, São Miguel do Araguaia e Nova Crixás, situados à noroeste do estado de Goiás (IBAMA, 1997, 2005; Carvalho, 2006; Agetur, 2020). Essa atividade resulta, também, em benefício para a população local, os ribeirinhos, que contam com ganhos extras no período de temporada de praias (de julho a agosto), pois têm a oportunidade de trabalharem como barqueiros e guias nas atividades de apoio em bares, restaurantes e hotéis (IBAMA, 1997, 2005; Agetur, 2020).
O turismo desordenado nas áreas reprodutivas de espécies de quelônios amazônicos - no caso, da tartaruga-da-amazônia (Podocnemis expansa) e do tracajá ( $P$. unifilis) - que ocorrem no Araguaia, pode ocasionar distúrbios durante o processo de nidificação dessas espécies. Esses podocnemidídeos são altamente seletivos quanto aos sítios de desova (praias e margens barranco e mata ciliar), razão pela qual pequenas alterações ou distúrbios nesses sítios, especialmente nas praias, local exclusivo de desova da tartarugada-amazônia, podem motivar declínio nas taxas de natalidade da espécie (Vogt, 2008; Balestra, 2016; Lacava \& Balestra, 2019).

Dentre os fatores impactantes que prejudicam o processo reprodutivo desses animais, destacamse a poluição causada pelo barulho dos motores de popa, jet-skis, geradores, fogos de artifício, sons das festas nos acampamentos; sanitários inadequados; consumo dos animais, especialmente de fêmeas reprodutoras; retirada da vegetação nativa para construção dos acampamentos; desinformação sobre as leis que protegem o meio ambiente em geral, notadamente quanto à pesca e proteção da fauna silvestre; e o ato inconsequente de depositar lixo nas praias e margem dos rios (IBAMA, 2004; Carvalho, 2006; Balestra, 2016; Lacava \& Balestra, 2019).

As principais adversidades desses quelônios decorrem das vulnerabilidades natas serem potencializadas por intervenções antrópicas, por meio de históricos, diversificados e severos meios de alteração de habitat, destacando-se os barramentos de corpos d'água com a construção de represas que prejudicam a migração dessas espécies a jusante ou a montante de sítios de nidificação; as queimadas e os desmatamentos das várzeas e matas ciliares, que são fontes de abrigo e alimentos; aterramento e compactação de áreas alagadas para plantações e manejo de gado; expansão das atividades agropastoris em substituição a florestas nativas; as perturbações decorrentes do turismo desordenado nas áreas de nidificação; entre outros fatores (Vogt, 2008; Lacava \& Balestra, 2019).

Naturalmente, o equilibrio populacional das espécies de quelônios, em geral, é dificultado em razão do ciclo de vida longo, em que a maturidade sexual é atingida tardiamente, resultando em baixa taxa de substituição de indivíduos na população. Por conta disso, a manutenção de populações naturais saudáveis depende da existência de uma quantidade viável de animais sexualmente 
maduros, principalmente fêmeas reprodutoras, que são as mais caçadas por possuírem maior tamanho corporal e maior susceptibilidade à apanha durante a desova, notadamente entre os podocnemidídeos. Embora a captura de adultos e a coleta de ovos de quelônios sejam proibidas pela legislação brasileira, essa é uma prática comum na Amazônia ainda nos dias de hoje. Praias que não são protegidas podem ter até $100 \%$ de predação de seus ovos (Vogt, 2008; Balestra, 2016).

Observando a necessidade do uso correto dos recursos naturais e conservação do meio ambiente, o extinto Instituto Brasileiro de Desenvolvimento Florestal (IBDF) implantou, em 1979, o Projeto Quelônio da Amazônia (PQA), com objetivo de proteção e manejo, criação em cativeiro, pesquisa e educação ambiental voltados para a conservação de espécies cinegéticas de quelônios de água doce da Amazônia Legal, sendo implantado no estado de Goiás em 1985 (IBAMA, 1997, 2002, 2004). Em 1994, o IBAMA iniciou o levantamento socioambiental nos municípios goianos próximos ao rio Araguaia e, ao mesmo tempo, o trabalho de orientação dos turistas campistas, quanto à melhor forma de se comportar durante as férias no rio, de maneira a causar menor impacto ambiental.

Esse trabalho, denominado "Ordenamento do Turismo e Ecoturismo no Rio Araguaia", foi coordenado e realizado pelo Núcleo de Educação Ambiental (NEA) do Centro Nacional de Pesquisa e Conservação de Répteis e Anfibios (RAN), em parceria com órgãos ambientais do estado de Goiás, com organizações não governamentais e voluntários (estudantes universitários). A iniciativa visou colaborar com a proteção do ecossistema fluvial e da herpetofauna regional, notadamente a tartaruga-daamazônia ( $P$. expansa), o tracajá ( $P$. unifilis), o jacaréaçu (Melanosuchus niger) e o jacaretinga (Caiman crocodilus), ameaçados pelos impactos antrópicos resultantes, principalmente, do turismo de massa na alta temporada de praias do Araguaia, no período das férias escolares de julho.

O projeto teve início com o cadastramento dos acampamentos montados nas praias, o qual é realizado anualmente. Na ocasião, também se aplica um questionário aos responsáveis pelos acampamentos para gerar informações sobre a relação dos campistas com o ambiente e sobre as instalações dos acampamentos. Esse trabalho possibilita a aproximação amistosa de agentes ambientais, institucionais ou voluntários, junto aos turistas, facilitando as ações de educação ambiental dos técnicos do NEA/RAN e seus parceiros, que transmitem informações e orientações visando harmonizar a atividade turística $e$ a conservação do meio ambiente (IBAMA, 2004; Carvalho, 2006; Lacava \& Balestra, 2019).

Nesse contexto, a partir do envolvimento das instituições e da sociedade, em 1996, foram criadas as Normas de Convivência com o rio Araguaia (Anexo), que foram definidas em reuniões realizadas antes da temporada de praia daquele ano, em prévio acordo, especialmente com os campistas que tradicionalmente utilizam os balneários da região do médio Araguaia para acampamentos de beira-rio, convidados de forma direcionada e por chamamentos públicos a qualquer interessado, de caráter facultativo $e$ voluntário, tornando-se, na prática, um código de conduta, que ano a ano é avaliado. As normas definem atitudes que devem ser tomadas e outras reprimidas, visando a harmonia entre o turismo $e$ a conservação do meio ambiente (IBAMA, 1997; 2004; 2005; Lacava \& Balestra, 2019).

$\mathrm{O}$ presente trabalho objetivou avaliar o comportamento turístico em temporadas de praia na região do médio rio Araguaia, a partir da vigência e evolução das normas de convivência com o rio Araguaia, analisando a efetividade das ações de educação ambiental promovidas pelo projeto "Ordenamento do Turismo e Ecoturismo no Rio Araguaia".

\section{Metodologia \\ Área de estudo}

Os questionários analisados neste estudo foram aplicados aos responsáveis pelos acampamentos de turistas, montados no rio Araguaia, num trecho de, aproximadamente, $480 \mathrm{~km}$ ao longo do rio, compreendido na região denominada médio Araguaia, situado na divisa dos estados de Goiás e Mato Grosso, entre a Reserva Extrativista (RESEX) Lago do Cedro, município de Aruanã/GO, passando pelo interior da Área de Proteção Ambiental (APA) Meandros do Rio Araguaia, no distrito e Luís Alves, município de São Miguel do Araguaia/GO, e distrito de São José dos Bandeirantes, município de Nova Crixás/ GO, até o entorno do Parque Nacional (PARNA) do Araguaia, na Ilha do Bananal, na divisa com o Tocantins (Figura 1). 


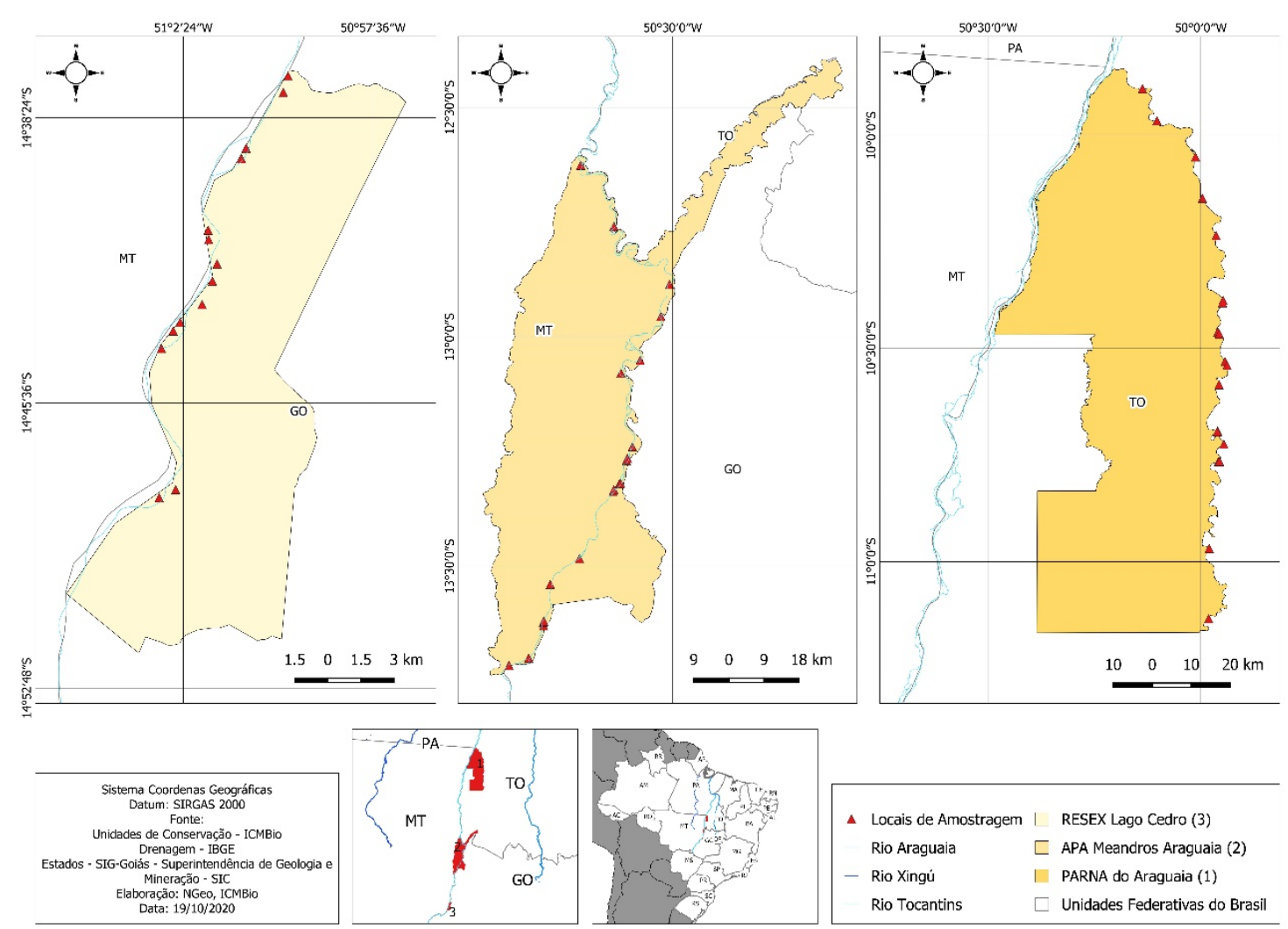

Figura 1 - Destaque dos principais locais (pontos de coletas de dados) de aplicação dos questionários nas unidadesde conservação federais alvo do projeto, por concentrarem a maioria dos acampamentos de praia monitorados na região do médio rio Araguaia.

\section{Análise de dados}

Foi caracterizada a evolução na forma de acampar e avaliado a mudança de comportamento $e$ atitudes perante o meio ambiente, concomitantes às ações de educação ao longo do tempo de vigência do projeto "Ordenamento do Turismo e Ecoturismo no Rio Araguaia". Para tanto, buscouse a análise dos questionários aplicados aos turistas da região do médio rio Araguaia, realizado em duas décadas, compreendendo o período 1993 a 2012 (último ano de execução do projeto), contabilizando um total de 2.695 questionários aplicados arquivados em pastas físicas na sede do RAN, sendo possível consolidar e avaliar, neste estudo, 1.913 desses questionários, contemplando o período de 1993 a 2005.

Apesar da evolução das normas de convivência com o rio Araguaia e, ato contínuo, das adequações do conteúdo do questionário para caracterização e avaliação das condutas dos campistas perante essas normas, as alterações se deram apenas com o aumento das normas e suas exigências, o que refletiu no aumento do número de questões pertinentes ao questionário, não tendo ocorrido deleção de normas ou de questões pretéritas. Neste sentido, o esforço amostral se manteve padronizado quanto à composição constante de agentes monitores capacitados na metodologia empregada e na quantificação $e$ qualificação, conforme padrão de abordagem, do número de acampamentos montados em cada unidade amostral (praia), por ano.

A procedência dos responsáveis pelos acampamentos também foi avaliada. Para comparação das respostas quanto ao destino do lixo produzido nos acampamentos e material utilizado na sua estrutura, foi utilizado o índice de Constância (C) de Dajoz (1972) apud Soares (2005), que consiste na porcentagem que determinada resposta aparece durante os anos que foram aplicados os questionários. Esse índice foi aplicado considerando as respostas antes das normas de convivência com o rio Araguaia, de 1994 a 1996 (C1); após a implementação dessas normas, de 1997 a 2005 (C2), exceto o ano de 2001; e durante os 11 anos amostrados (C3).

$$
C=(P \times 100) \div N
$$


Onde $\mathrm{P}$ é o número de anos em que aparece a resposta estudada e $\mathrm{N}$ é o número de anos trabalhados.

As repostas presentes durante os anos selecionados foram separadas nas seguintes classificações:

A) Resposta constante: presente em mais de 50 $\%$ dos anos;

B) Resposta esporádica: presente em $25 \%$ a 50 $\%$ dos anos;

C) Resposta rara: presente em menos de $25 \%$ dos anos.

\section{Sistematização de dados}

O último modelo de questionário utilizado até o fim do projeto em 2012 foi aprimorado com base nos resultados e recomendações de um projeto $\mathrm{PIBIC/ICMBio} \mathrm{que} \mathrm{propôs} \mathrm{facilitar} \mathrm{a}$ inclusão das informações em banco de dados. Para isso, houve um esforço em desenhar uma ferramenta útil para colher e apresentar os dados cadastrados na forma de informações aplicáveis na gestão do ordenamento turístico da região de interesse. Utilizaram-se os próprios mecanismos existentes no sistema computacional de uso comum do órgão, sendo este aplicativo o Microsoft Acess 2010 for Windows.

Buscou-se uma integração entre o layout desse aplicativo e o documento original, ou seja, a ficha de cadastramento dos campistas e ribeirinhos, para que se organizassem as perguntas $e$ as respostas em ordem, de modo a facilitar a inserção dos dados, compreendendo 64 questões com respostas pré-determinadas no sistema, que intercruzavam informações correlatas, em três níveis de seções:

1) Layout: interface na qual se inserem os dados pertinentes às 64 perguntas fundamentais.

2) Tabelas: espaço organizacional onde os dados $e$ as respostas às perguntas dos questionários são armazenados, conforme sua origem $e$ função no banco de dados.

3) Consultas: espaço analítico dos dados onde se projetam as relações entre as tabelas, gerando gráficos que traduzem quantitativamente as informações consolidadas.

\section{Resultados e Discussão}

\section{Fases do projeto}

Até o ano de 2012, com o término do projeto "Ordenamento do Turismo e Ecoturismo no Rio Araguaia", foram monitorados 4.697 acampamentos em praias na região de interesse, especialmente nas localidades destacadas na Figura 1; contudo, quanto à organização e análise de dados, neste trabalho é apresentada uma avaliação detalhada, limitada ao que foi possível ser sistematizado até a ocasião, dos 11 primeiros anos de execução do projeto, compreendendo os dados de 1.913 questionários aplicados entre os anos de 1993 a 2005 (exceto 2001, em que, por motivos administrativos, não houve essa atividade), relativos ao monitoramento dos acampamentos montados anualmente nas praias dessa região do rio Araguaia, na época da chamada localmente "temporada" de praia (Carvalho, 2006). Essa época ocorre no mês de julho, no período de estiagem (seca), ocasião em que afloram os bancos arenosos às margens do rio. Tais informações propiciaram a caracterização do perfil histórico dos atributos e contribuições do projeto em questão.

No esforço de divulgar as normas de convivência com o rio Araguaia, um acordo firmado entre os responsáveis de acampamento, que visava a preservação do ambiente físico, da flora, da fauna e o bem-estar dos turistas, buscou-se sensibilizar os campistas quanto aos cuidados ambientais, além de orientar e intervir em casos de descumprimento das normas ou ocorrência de crime ambiental. A partir da aplicação de questionários e de observações in situ foi produzida uma ficha de coleta de dados, para posterior análise. Esse material, referente a dados coletados de 1993 a 2012, encontrava-se disponível apenas em arquivo físico. Os questionários de coleta de dados foram sendo aperfeiçoados, ao longo dos períodos de avaliação, para melhor compreensão da prática do camping de férias no rio Araguaia.

As análises das mudanças nos modelos de questionários utilizados no projeto e dos produtos realizados, como relatórios técnicos, textos informativos, trabalhos científicos, entre outros revelaram a existência de três períodos ou fases distintas em relação à metodologia de abordagem e ao detalhamento das informações colhidas, quais seja: 


\section{a) Projeto Araguaia, de 1993 a 1995}

No início, visando principalmente a proteção da tartaruga-da-amazônia (Podocnemis expansa) propostas pelo Projeto Quelônios da Amazônia, as atividades desenvolvidas na região do médio rio Araguaia focavam a aplicação de um questionário, a fim de cadastrar os acampamentos, e um convite para confraternização, utilizando-se de instrumentos musicais, cantigas, brincadeiras, distribuição de brindes, estímulo de gratidão à natureza $e$ demonstração de afeto entre os campistas. Após essa abordagem, seguia o aconselhamento sobre o que fazer e o que não fazer para cuidar melhor da saúde do rio (metodologia: educação ambiental informativa e conservacionista).

Esse trabalho teve um papel desbravador em relação à educação ambiental, pois despertou os turistas e a população local em geral para os problemas ambientais que comprometiam a conservação dos recursos naturais providos (peixes, tartarugas, jacarés etc.) ou intimamente relacionados ao rio, como a mata ciliar. O sucesso alcançado deu-se, basicamente, no nível informativo, com a caracterização dos maiores problemas da relação homem $\mathrm{x}$ natureza, o que foi fundamental para os avanços nos processos evolutivos da intervenção da educação ambiental na região.

Contudo, não gerou, até o ano de 1995, mudanças significativas de comportamento nas ações práticas, visto que não houve, por parte dos campistas, a tendência de se comprometer com regras alheias, de cuja construção não participaram.

\section{b) Projeto Araguaia, de 1996 a 2007}

Esta fase compreende os questionamentos $e$ a avaliação do trabalho anteriormente realizado. Percebeu-se que a metodologia utilizada não estava produzindo efeitos práticos, nem mesmo no curto prazo, configurando-se apenas em informações avulsas. No entanto, com a saída dos agentes ambientais, os comportamentos e atitudes prejudiciais ao meio ambiente voltavam a serem verificados. Portanto, havia a necessidade de se buscarem novas metodologias para a abordagem ao turista.
Foi proposta, então, uma metodologia mais participativa que protagonizasse os turistas $e$ moradores locais nos processos de planejamento e realização das ações educativas relativas ao melhor comportamento para conservação dos recursos naturais dos balneários frequentados (IBAMA, 1997; 2004; 2005). No ano de 1997, iniciou-se a participação dos ribeirinhos $e$ responsáveis de acampamento no planejamento do projeto com diversas reuniões de entrosamento e repasse de informações, quando se começou a pensar conjuntamente os problemas relativos às intervenções dos campistas $e$ à preservação ambiental regional.

Esse planejamento participativo era realizado nas praias do rio, com reuniões nos acampamentos, com turistas e ribeirinhos. A partir de 1997, além do planejamento conjunto nas praias, foram implantadas reuniões anuais em Goiânia e São Miguel do Araguaia/GO. Nesses encontros formais de trabalho, conduzidos de forma participativa tanto por grupos técnicos de profissionais atuantes em diversas áreas do meio ambiente, quanto por representantes dos acampamentos e da sociedade interessada, começaram a ser delineadas as normas de convivência com o rio Araguaia, contando com a participação de responsáveis de acampamentos, instituições ambientais, ONGs, representantes de comunidades ribeirinhas e estudantes universitários. Nessas reuniões, realizava-se o planejamento anual e dava-se continuidade à construção das normas de convivência (Carvalho, 2006).

Os resultados das reuniões, desde então, foram divulgados na mídia $e$ apresentados às comunidades ribeirinhas das regióes que margeiam o rio Araguaia (IBAMA, 1997). Durante as primeiras reuniões, evidenciaram-se inconsistências na metodologia do trabalho. Apesar de os órgãos terem os mesmosobjetivos, asformas de abordagem aos campistas causavam certa confusão. Estes reclamavam que respondiam a vários cadastros $e$, às vezes, no mesmo dia, recebiam informações contraditórias e procedimentos diferenciados das várias entidades públicas e ONGs envolvidas (IBAMA, 1997; Carvalho, 2006).

A partir dessas observações, os órgãos ambientais optaram por alinhar suas formas de abordagem, a começar pelo repasse das informações nos meios de comunicação. 
Panfletos, cartilhas e outros materiais foram produzidos, nos quais constavam os nomes de todos os parceiros ambientais que atuavam no rio Araguaia (IBAMA, 1997).

A partir dessas reuniões, foram acordadas com os campistas várias mudanças de comportamento, no que se refere, por exemplo, à construção dos acampamentos, destinação do lixo e construção de instalações sanitárias. Desde então, houve uma grande integração entre os órgãos ambientais $e$ os responsáveis por acampamentos. Esse acordo, implementado a partir da temporada de 1997, recebeu a denominação oficial de Normas de Convivência com o Rio Araguaia. No mesmo ano, foi instituído o Certificado de Parceiro do Rio Araguaia, destinado aos acampamentos que cumprissem as normas de convivência e atendessem aos critérios estabelecidos pelos avaliadores do RAN (IBAMA, 1997; 2002; 2004; Carvalho, 2006).

É importante ressaltar que o projeto sofreu uma descontinuidade em 2001, em decorrência da mudança das atividades do RAN (questões administrativas). Isso provocou rupturas nas metas, prioridades e resultados do projeto. Em 2002, quando se reativou o trabalho, foi necessário recomeçar muitas ações e até mesmo restabelecer laços de confiança com a comunidade e com as ONGs.

Em 2004 e 2005, contou-se com a participação ativa de alunos da Universidade Católica de Goiás (UCG), Universidade Estadual de Goiás (UEG), Universidade Federal de Goiás (UFG) e universidades de outros estados. Esses alunos fizeram um curso de capacitação em educação ambiental, voltado para a aplicação da metodologia utilizada nas atividades desenvolvidas junto aos turistas, tendo como base as mencionadas normas de convivência, o qual foi ministrado pelo NEA/RAN. O aporte desses voluntários possibilitou a ampliação do projeto, que passou a ser oferecido também fora da área da APA Meandros do rio Araguaia.

\section{c) Projeto Araguaia, de 2008 a 2012}

Com as normas de convivência com o Rio Araguaia consolidadas, bem conhecidas pelos campistas contumazes e bem disseminadas entre os novos campistas, iniciou-se uma nova abordagem, sendo adotada uma postura de cobrança de comportamento em consonância com essas normas de convivência e de notificação, estabelecendo-se um prazo razoável para adequação e essas normas.
A ficha de coleta de informações, denominada "cadastro de acampamentos", foi analisada $e$ verificou-se inconsistência quanto aos critérios $e$ quanto à fundamentação teórica do processo de certificação dos acampamentos, visto que a mesma não formulava todas as questões necessárias à certificação pretendida.

$\mathrm{Na}$ primeira fase (1993-2000), foi utilizado um questionário simplificado, com 14 questões, verificando apenas 5 das 15 normas de convivência com o rio. Na segunda fase (20022007), foi utilizado um questionário com 32 questões, verificando 7 das 15 normas em questão. Na terceira fase (2008-2012), com todas as normas consolidadas, elaborou-se um questionário com 65 questões, visando verificar se todas as 15 normas estavam sendo cumpridas. Foi, então, desenvolvido um novo modelo de cadastro capaz de coletar todos os dados sobre o cumprimento das normas de convivência para subsidiar eficientemente a certificação dos acampamentos adequados a essas normas (Freitas, 2008).

A utilização desse modelo de questionário/ cadastro foi validada pelo NEA/RAN e, de julho de 2008 a julho de 2012 (ano de encerramento do projeto), foi usado na coleta de dados.

Até a conclusão do presente deste estudo, foi realizada a transferência ou o registro parcial dos dados dos questionários arquivados na sede do RAN para o formato digital, equivalente aos anos de 1993 a 2005, utilizando-se uma plataforma estruturada por campos condizentes com as perguntas feitas aos responsáveis de acampamentos.

\section{Análise de dados e perfil do comportamento ambiental dos praticantes de campismo de praia no rio Araguaia}

Os acampamentos monitorados até o ano 2012 (4.697) estão assim distribuídos: 1.017 $(21,65 \%)$ em Aruanã/GO, às margens e interior da RESEX Lago do Cedro; 330 (7,03\%) em Cocalinho/MT, no entorno da APA Meandros do Rio Araguaia; $1.784(37,98)$ em Luiz Alves/GO, no interior da APA Meandros do Rio Araguaia; 611 $(13,01 \%)$ na Ponta Sul da Ilha do Bananal/TO, às margens e interior do PARNA do Araguaia; $e$ 955 (20,23\%) em São José dos Bandeirantes/GO, entre a RESEX Lago do Cedro e a APA Meandros do Rio Araguaia (Tabela 1). 
Tabela 1 - Distribuição de acampamentos nos municípios da região monitorada.

\begin{tabular}{|c|c|c|c|c|c|}
\hline Localização & $1^{a}$ fase & $2^{a}$ fase & $3^{\text {a }}$ fase & Total & $\%$ \\
\hline Aruanã & $\ldots .$. & 19 & 998 & 1.017 & 21,65 \\
\hline Bandeirantes & 207 & 469 & 279 & 955 & 20,33 \\
\hline Cocalinho & $\ldots \ldots$ & 45 & 285 & 330 & 7,03 \\
\hline Luis Alves & 646 & 646 & 492 & 1.784 & 37,98 \\
\hline $\begin{array}{l}\text { Ponta Sul da } \\
\text { Ilha do } \\
\text { Bananal }\end{array}$ & 259 & 252 & 100 & 611 & 13,01 \\
\hline Total & 1.112 & 1.431 & 2.154 & 4.697 & 100 \\
\hline
\end{tabular}

O público total atingindo pelas atividades de educação ambiental do NEA/RAN, durante as temporadas de praia no médio Araguaia, em 20 anos de projeto, foi de cerca de 115.078 turistas (Tabela 2).

Tabela 2 - Total de campistas alcançados pelas atividades de educação ambiental.

\begin{tabular}{|c|c|c|c|c|c|}
\hline Localização & $1^{\text {a }}$ fase & $2^{a}$ fase & $3^{a}$ fase & Total & $\%$ \\
\hline Aruanã & $\ldots .$. & 437 & 32.994 & 33431 & 29,05 \\
\hline Bandeirantes & 3.959 & 10.797 & 6.156 & 20912 & 18,17 \\
\hline Cocalinho & $\ldots .$. & 1057 & 5367 & 6424 & 5,58 \\
\hline Luis Alves & 10.153 & 11.587 & 16.991 & 38731 & 33,66 \\
\hline $\begin{array}{l}\text { Ponta Sul da } \\
\text { Ilha do } \\
\text { Bananal }\end{array}$ & 5.973 & 6019 & 3.588 & 15580 & 13,54 \\
\hline Total & 20.085 & 29.897 & 65.096 & 115.078 & 100 \\
\hline
\end{tabular}

Em 1.835 (95,92\%) questionários avaliados que continham respostas sobre a procedência do responsável pelos acampamentos, observou-se que o maior número é do estado de Goiás, 1649 (89,70\%); em seguida, está o Distrito Federal, com 136 responsáveis (7,41\%); e, em terceiro lugar, curiosamente, em razão da distância, com 21, está São Paulo (1,14\%). Os estados de Minas Gerais, Rondônia, Mato Grosso, Espírito Santo e Tocantins somaram 29 responsáveis $(1,58 \%)$ (Figura 2$)$.

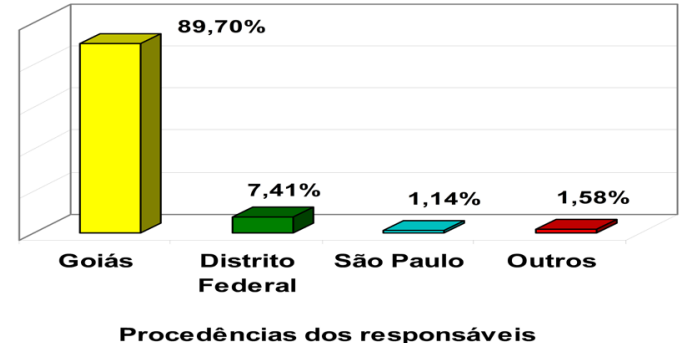

Figura 2 - Procedência dos responsáveis pelos acampamentos ( $\mathrm{n}=1835)$.

Dos $1.746(91,27 \%)$ questionários avaliados que continham informações sobre o destino dado ao lixo produzido nos acampamentos, 1.031 questionários $(59,05 \%)$ informaram que o lixo inorgânico (LI) era levado para cidade, assim como $247(14,15 \%)$ informaram que tanto o Lixo Inorgânico (LI), como o Orgânico (LO) eram levados para a cidade. Outra resposta bastante frequente foi enterrar o LO e levá-lo para a cidade o LI ( $\mathrm{n}=132 ; 7,56 \%$ ) (Tabela 3$)$.

Analisando-se as respostas através do índice de Constância (C) e a respectiva classificação antes e após a implementação das normas de convivência com o rio Araguaia $(\mathrm{C} 1$ = de 1994 a 1996; C2 = de 1997 a 2005), respectivamente, observa-se que algumas respostas relacionadas às atitudes prejudiciais ao meio ambiente passaram de constantes $(\mathrm{A})$ para esporádicas $(\mathrm{B})$ ou raras $(\mathrm{C})$, como foi o caso de enterrar o $\mathrm{LO}$ e queimar o LI, e queimar o LO e LI (Tabela 4).

Por outro lado, atividades positivas que antes das normas eram raras, passaram para esporádicas ou constantes, como foi o caso de levar o LO e LI para a cidade $(14,15 \%)$ e a coleta pela prefeitura do LO e LI (6,70\%) (Tabelas 3 e 4). No entanto, a resposta mais comum, levar o LI para a cidade, foi constante nos questionários, tanto antes como depois das normas de convivência (Tabela 4).

A orientação dada aos responsáveis pelos acampamentos foi para que o LO fosse enterrado no barranco e o LI levado para a cidade mais próxima. Observa-se na Tabela 3 que essa atitude ficou em terceiro lugar ( $n=132 ; 7,56 \% ; N=1746)$ $e$, ainda, de acordo com o índice de Constância, foi classificada como uma resposta constante, tanto antes, como depois das normas de convivência ( $\mathrm{C} 1$ $=66,66 \%$; C2 = 100\%; C3 = 90,90\%) (Tabela 4). Embora a atitude de deixar o LO e LI na praia tenha representado apenas $2,24 \%$ das respostas $(n=39 ; N$ $=1746$ ), essa também foi uma resposta constante nos questionários ( $\mathrm{C} 1=66,66 \%$; $\mathrm{C} 2=62,50 \%$; C3 $=63,63 \%$ ) (Tabelas 3 e 4). 
Dos destinos dados ao lixo, 17 poluem o meio ambiente, como queimar o lixo, jogar no rio, enterrar LI e deixar o lixo na praia, somando 495 respostas dos questionários (N $=1746$ ). Já as ações positivas, como levar o lixo para a cidade, a prefeitura ou associação de barqueiros recolher e enterrar o LO, totalizaram 1.018 respostas $(61,74 \%)$, sendo excluídas as respostas que não deram informações exatas (Tabela 03).

Vale ressaltar que, embora as atitudes como jogar o LO no rio e levar LI para a cidade (1,09\%); queimar o LO e o LI levar para a cidade $(0,11 \%)$; deixar LO na praia $e$ levar LI para a cidade $(1,77 \%)$; e jogar o LO no rio e queimar o $\operatorname{LI}(0,23 \%)$, não tenham sido comuns no universo de 1.746 respostas, foram classificadas como esporádicas - ou seja, estiveram presentes em $25 \%$ dos anos trabalhados, mesmo após a implementação das normas de convivência (C2) (Tabelas 3 e 4). A coleta realizada pela associação de barqueiros representou $1,77 \%$ da destinação do lixo ( $\mathrm{n}=31 ; \mathrm{N}=1746$ ), e foi classificada como rara, tanto antes como depois das normas $(\mathrm{C} 1=0 \%$; $\mathrm{C} 2=12,5 \%$; $\mathrm{C} 3=9,09 \%)$.

A destinação do lixo cuja informação foi "outros", somada, representou $1,20 \%$, e foram classificadas como respostas raras ao longo dos anos, tanto antes como depois da implementação das normas (Tabelas 3 e 4). Este tipo de resposta não identifica a ação, no entanto, somente em 2004 ocorreram mudanças no conteúdo dos questionários, essa evolução foi necessária a fim de se obter informações que de fato interessavam, e de forma organizada, para que pudessem ser quantificadas e qualificadas, quando da análise dos questionários.

Em relação à escolha do material utilizado na estrutura dos acampamentos, dos 1913 questionários analisados, 1696 (88,66\%) apresentaram respostas referentes ao material utilizado na estrutura dos acampamentos (Tabela 5). O material mais utilizado foi madeira beneficiada com 442 respostas $(26,06 \%)$, sendo uma resposta constante nos questionários, tanto antes como depois das normas de convivência ( $\mathrm{C} 1=66,66 \%$; C2 $=100 \%$; C3 = 90,90\%) (Tabelas 5 e 6).
A estrutura metálica foi o segundo material mais usado pelos campistas, com 361 respostas (21,28\%), sendo uma resposta esporádica antes das normas de convivência; e constante, depois das normas ( $\mathrm{C} 1=33,33 \%$; $\mathrm{C} 2=100 \%$; $\mathrm{C} 3=$ $81,81 \%$ ); em seguida, vem o bambu, $\mathrm{n}=207$ (15,92\%), sendo também esporádica antes das normas de convivência, e constante depois das normas $(\mathrm{C} 1=33,33 \%$; $\mathrm{C} 2=87,5 \%$; $\mathrm{C} 3=$ 72,72\%) (Tabelas 5 e 6).

Autilização somente da barraca de camping não foi o modelo mais utilizado ( $\mathrm{n}=169 ; 9,96 \%$; $\mathrm{N}=1696$ ); contudo, foi a resposta mais constante ao longo dos anos (C1; C2 e C3 iguais a 100\%) (Tabelas 5 e 6). A utilização da madeira nativa, tanto antes quanto depois das normas de convivência, foi constante $(\mathrm{C} 1=66,66 \%$; $\mathrm{C} 2=100 \%$ e C3 $=90,9 \%$ ), muito embora não se configure entre as mais utilizadas ( $\mathrm{n}=57 ; 3,37 \% ; \mathrm{n}=1696$ ). Das 29 respostas referentes ao material utilizado na estrutura de acampamento, 10 indicam o uso da madeira nativa extraída das margens do Araguaia. Juntas totalizam, ao longo dos 11 anos de projeto avaliados, 95 acampamentos (5,60\%; $N=1696)$ (Tabelas 5 e 6).

Exceto as respostas que não informam quanto ao tipo de material utilizado (p. ex., rancho), o restante das respostas indica a utilização de materiais adequados às normas de convivência. Juntas representam a resposta dada por 1385 acampamentos $(81,66 \%)$ ao longo de 11 anos avaliados de trabalho do NEA/ RAN (Tabela 5).

O PVC é um material que foi utilizado somente a partir de 2005, com apenas uma resposta. A estrutura "rancho", com 65 respostas (3,83\%), $\neg \neg$ foi constante nos questionários antes das normas de convivência $(C 1=100 \%)$, mas, depois das normas, passou para rara $(\mathrm{C} 2=12,5 \%)$, pois como não é uma resposta que indique especificamente de qual material é feito a estrutura, foi eliminada dos questionários a partir de 1997.

A opção "outros" ocorreu em 36 questionários (2,12\%); no entanto, é uma resposta esporádica $(\mathrm{C} 1=33,33 \%$; $\mathrm{C} 2=37,5 \%$ e $\mathrm{C} 3=$ $36,36 \%$ ), felizmente, pois não traz informações sobre o material empregado na estrutura dos acampamentos. 
Tabela 3 - Destino dado ao lixo produzido pelos acampamentos montados nas praias do médio rio Araguaia.

\begin{tabular}{|c|c|c|c|c|c|c|c|c|c|c|c|c|}
\hline Destino & 1994 & 1995 & 1996 & 1997 & 1998 & 1999 & 2000 & 2002 & 2003 & 2004 & 2005 & Total \\
\hline Enterram & 7 & 0 & 3 & 1 & 2 & 0 & 1 & 1 & 1 & 0 & 0 & 16 \\
\hline LI levam p/cidade & 14 & 1 & 35 & 155 & 150 & 167 & 184 & 150 & 164 & 1 & 10 & 1031 \\
\hline LO enterram & 0 & 3 & 0 & 0 & 0 & 0 & 0 & 0 & 0 & 0 & 0 & 4 \\
\hline LO enterram e LI queimam & 11 & 0 & 1 & 0 & 0 & 0 & 0 & 0 & 0 & 0 & 0 & 13 \\
\hline LO enterra e LI levam p/ cidade & 0 & 2 & 5 & 2 & 24 & 7 & 3 & 3 & 7 & 34 & 45 & 132 \\
\hline $\begin{array}{l}\text { LO enterram e LI prefeitura } \\
\text { colera }\end{array}$ & 0 & 0 & 0 & 0 & 0 & 0 & 0 & 14 & 0 & 0 & 0 & 14 \\
\hline LO enterram e LI outros & 0 & 0 & 0 & 0 & 0 & 0 & 0 & 0 & 0 & 0 & 1 & 1 \\
\hline LO jogam no rio e LI outros & 0 & 0 & 0 & 0 & 0 & 0 & 0 & 0 & 0 & 0 & 1 & 1 \\
\hline LO jogam no rio e LI queimam & 0 & 0 & 0 & 0 & 0 & 0 & 0 & 0 & 0 & 2 & 2 & 4 \\
\hline $\begin{array}{l}\text { LO jogam no rio e LI prefeitura } \\
\text { coleta }\end{array}$ & 0 & 0 & 0 & 0 & 0 & 2 & 0 & 0 & 0 & 0 & 0 & 2 \\
\hline LO jogam no rio e LI enterram & 0 & 0 & 1 & 0 & 0 & 0 & 0 & 0 & 0 & 0 & 2 & 3 \\
\hline $\begin{array}{l}\text { LO jogam no rio e LI levam } \mathrm{p} / \\
\text { cidade }\end{array}$ & 0 & 0 & 1 & 0 & 0 & 0 & 0 & 1 & 0 & 17 & 0 & 19 \\
\hline $\begin{array}{l}\text { LO queimam e LI levam p/ } \\
\text { cidade }\end{array}$ & 0 & 0 & 0 & 0 & 0 & 0 & 1 & 0 & 0 & 1 & 0 & 2 \\
\hline $\begin{array}{l}\text { LO deixam na praia e LI levam } \\
\text { p/ cidade }\end{array}$ & 0 & 0 & 0 & 0 & 0 & 0 & 0 & 0 & 0 & 5 & 26 & 31 \\
\hline $\begin{array}{l}\text { LO deixam na praia e LI } \\
\text { enterram }\end{array}$ & 0 & 0 & 0 & 0 & 0 & 0 & 0 & 0 & 0 & 0 & 5 & 5 \\
\hline LO deixam na praia e LI outros & 0 & 0 & 0 & 0 & 0 & 0 & 0 & 0 & 0 & 0 & 1 & 1 \\
\hline $\begin{array}{l}\text { LO levam p/ cidade e LI } \\
\text { queimam }\end{array}$ & 0 & 0 & 0 & 0 & 0 & 0 & 0 & 0 & 0 & 155 & 1 & 2 \\
\hline LO e LI levam p/ cidade & 0 & 0 & 0 & 0 & 0 & 0 & 0 & 0 & 0 & 0 & 92 & 247 \\
\hline $\mathrm{LO}$ e LI queimam & 1 & 2 & 0 & 0 & 0 & 0 & 2 & 0 & 0 & 0 & 1 & 6 \\
\hline LO e LI deixam na praia & 11 & 0 & 2 & 1 & 0 & 0 & 0 & 2 & 1 & 15 & 7 & 39 \\
\hline LO e LI prefeitura coleta & 33 & 0 & 0 & 1 & 0 & 0 & 37 & 25 & 7 & 0 & 14 & 117 \\
\hline $\begin{array}{l}\text { LO ribeirinhos coletam e } \mathrm{LI} \\
\text { levam } \mathrm{p} \text { cidade }\end{array}$ & 0 & 0 & 0 & 0 & 0 & 0 & 0 & 0 & 0 & 1 & 0 & 1 \\
\hline LO outros LI enterram & 0 & 0 & 0 & 0 & 0 & 0 & 0 & 0 & 0 & 0 & 1 & 1 \\
\hline LO outros e LI deixam na praia & 0 & 0 & 0 & 0 & 0 & 0 & 0 & 0 & 0 & 0 & 1 & 1 \\
\hline LO e LI outros & 0 & 0 & 0 & 0 & 0 & 0 & 0 & 0 & 0 & 0 & 15 & 15 \\
\hline Jogam no rio & 0 & 0 & 0 & 0 & 0 & 0 & 0 & 1 & 6 & 0 & 0 & 7 \\
\hline Associação de barqueiros coleta & 0 & 0 & 0 & 0 & 0 & 0 & 0 & 0 & 31 & 0 & 0 & 31 \\
\hline Total & 77 & 8 & 48 & 160 & 176 & 176 & 228 & 197 & 217 & 233 & 226 & 1746 \\
\hline
\end{tabular}

Nota: $L O$ = lixo Orgânico; LI = lixo Inorgânico; e Outros = resposta inexata. 
Tabela 4 - Classificação das respostas referentes ao destino do lixo produzido pelos acampamentos, de acordo com o índice de Constância (C).

\begin{tabular}{|c|c|c|c|c|c|c|}
\hline Destino & $\mathrm{C} 1(\%)$ & Classificação & $\mathrm{C} 2(\%)$ & Classificação & C3(\%) & Classificação \\
\hline Enterram & 66,66 & A & 62,5 & A & 63,63 & A \\
\hline LI levam p/cidade & 100 & A & 100 & A & 100 & A \\
\hline LO enterram & 100 & A & 12,5 & $\mathrm{C}$ & 18,18 & $\mathrm{C}$ \\
\hline LO enterram e LI queimam & 66,66 & A & 12,5 & C & 27,27 & B \\
\hline LO enterra e LI levam p/ cidade & 66,66 & A & 100 & A & 90,9 & A \\
\hline LO enterram e LI prefeitura colera & 0 & $\mathrm{C}$ & 12,5 & $\mathrm{C}$ & 9,09 & $\mathrm{C}$ \\
\hline LO enterram e LI outros & 0 & $\mathrm{C}$ & 12,5 & $\mathrm{C}$ & 9,09 & $\mathrm{C}$ \\
\hline LO jogam no rio e LI outros & 0 & $\mathrm{C}$ & 12,5 & $\mathrm{C}$ & 9,09 & $\mathrm{C}$ \\
\hline LO jogam no rio e LI queimam & 0 & $\mathrm{C}$ & 25 & B & 18,18 & $\mathrm{C}$ \\
\hline LO jogam no rio e LI prefeitura coleta & 0 & $\mathrm{C}$ & 12,5 & C & 9,09 & C \\
\hline LO jogam no rio e LI enterram & 33,33 & $\mathrm{~B}$ & 12,5 & C & 18,18 & C \\
\hline LO jogam no rio e LI levam p/cidade & 33,33 & $\mathrm{~B}$ & 25 & B & 27,27 & B \\
\hline LO queimam e LI levam p/ cidade & 0 & $\mathrm{C}$ & 25 & $\mathrm{~B}$ & 18,18 & $\mathrm{C}$ \\
\hline LO deixam na praia e LI levam $\mathrm{p} /$ cidade & 0 & $\mathrm{C}$ & 25 & $\mathrm{~B}$ & 18,18 & $\mathrm{C}$ \\
\hline LO deixam na praia e LI enterram & 0 & $\mathrm{C}$ & 12,5 & $\mathrm{C}$ & 9,09 & $\mathrm{C}$ \\
\hline LO deixam na praia e LI outros & 0 & C & 12,5 & C & 9,09 & $\mathrm{C}$ \\
\hline LO levam p/ cidade e LI queimam & 0 & $\mathrm{C}$ & 25 & $\mathrm{~B}$ & 18,18 & $\mathrm{C}$ \\
\hline LO e LI levam p/ cidade & 0 & $\mathrm{C}$ & 25 & B & 18,18 & $\mathrm{C}$ \\
\hline LO e LI queimam & 66,66 & A & 25 & B & 36,36 & B \\
\hline LO e LI deixam na praia & 66,66 & A & 62,5 & A & 63,63 & A \\
\hline LO e LI prefeitura coleta & 33,33 & $\mathrm{~B}$ & 62,5 & A & 54,54 & A \\
\hline $\begin{array}{l}\text { LO ribeirinhos coletam e LI levam p/ } \\
\text { cidade }\end{array}$ & 0 & $\mathrm{C}$ & 12,5 & $\mathrm{C}$ & 9,09 & $\mathrm{C}$ \\
\hline LO outros LI enterram & 0 & $\mathrm{C}$ & 12,5 & $\mathrm{C}$ & 9,09 & $\mathrm{C}$ \\
\hline LO outros e LI deixam na praia & 0 & $\mathrm{C}$ & 12,5 & $\mathrm{C}$ & 9,09 & $\mathrm{C}$ \\
\hline LO e LI outros & 0 & C & 12,5 & C & 9,09 & C \\
\hline Jogam no rio & 0 & $\mathrm{C}$ & 25 & $\mathrm{~B}$ & 18,18 & C \\
\hline Associação de barqueiros coleta & 0 & $\mathrm{C}$ & 12,5 & $\mathrm{C}$ & 9,09 & $\mathrm{C}$ \\
\hline
\end{tabular}

Nota: A) resposta constante; B) esporádica; C) rara; C1) antes das normas de convivência; $\mathrm{C} 2$ ) depois das normas; C3) ao longo dos 11 anos trabalhados; LO = lixo orgânico e LI = lixo inorgânico; e outros = resposta inexata. 
Tabela 5 - Materiais utilizados na estrutura dos acampamentos de praia (beira-rio) no médio rio Araguaia, ao longo de 11 anos de projeto avaliados.

\begin{tabular}{|c|c|c|c|c|c|c|c|c|c|c|c|c|}
\hline Estrututa & 1994 & 1995 & 1996 & 1997 & 1998 & 1999 & 2000 & 2002 & 2003 & 2004 & 2005 & Total \\
\hline Bambu & 0 & 0 & 3 & 0 & 53 & 34 & 65 & 25 & 12 & 29 & 49 & 270 \\
\hline Bambu e barraca de camping & 0 & 0 & 0 & 0 & 0 & 2 & 3 & 0 & 0 & 1 & 3 & 9 \\
\hline $\begin{array}{l}\text { Bambu, barracas de camping } \\
\text { e madeira }\end{array}$ & 0 & 0 & 0 & 0 & 0 & 0 & 0 & 1 & 0 & 0 & 0 & 1 \\
\hline Barraca de camping & 4 & 7 & 10 & 76 & 21 & 14 & 10 & 10 & 15 & 1 & 1 & 169 \\
\hline Estrutura metálica & 0 & 0 & 3 & 1 & 53 & 35 & 32 & 48 & 69 & 70 & 50 & 361 \\
\hline Estrutura metálica e bambu & 0 & 0 & 0 & 0 & 0 & 0 & 3 & 1 & 1 & 6 & 9 & 20 \\
\hline Estrutura metálica e barraca & 0 & 0 & 0 & 1 & 0 & 8 & 10 & 4 & 0 & 2 & 1 & 26 \\
\hline $\begin{array}{l}\text { Estrutura metálica e madeira } \\
\text { nativa }\end{array}$ & 0 & 0 & 0 & 0 & 0 & 0 & 0 & 0 & 0 & 1 & 2 & 3 \\
\hline $\begin{array}{l}\text { Estrutura metálica, bambu e } \\
\text { madeira nativa }\end{array}$ & 0 & 0 & 0 & 0 & 0 & 0 & 0 & 0 & 1 & 1 & 0 & 2 \\
\hline $\begin{array}{l}\text { Estrutura metálica, bambu e } \\
\text { madeira beneficiada }\end{array}$ & 0 & 0 & 0 & 0 & 0 & 0 & 0 & 0 & 0 & 2 & 0 & 2 \\
\hline Madeira beneficiada & 2 & 0 & 3 & 2 & 29 & 54 & 57 & 71 & 93 & 64 & 67 & 442 \\
\hline Madeira beneficiada e bambu & 0 & 0 & 0 & 0 & 9 & 0 & 0 & 3 & 1 & 7 & 10 & 30 \\
\hline $\begin{array}{l}\text { Madeira beneficiada e barraca } \\
\text { de camping }\end{array}$ & 0 & 0 & 0 & 1 & 0 & 7 & 16 & 2 & 0 & 2 & 2 & 30 \\
\hline $\begin{array}{l}\text { Madeira beneficiada e estrutu- } \\
\text { ra metálica }\end{array}$ & 0 & 0 & 0 & 0 & 0 & 6 & 2 & 4 & 4 & 24 & 8 & 48 \\
\hline Madeira beneficiada e natica & 0 & 0 & 0 & 0 & 1 & 0 & 5 & 0 & 3 & 2 & 1 & 12 \\
\hline $\begin{array}{l}\text { Madeira beneficiada, barra- } \\
\text { ca de camping e estrutura } \\
\text { metálica }\end{array}$ & 0 & 0 & 0 & 0 & 1 & 1 & 2 & 1 & 0 & 0 & 0 & 5 \\
\hline $\begin{array}{l}\text { Madeira beneficiada, barraca } \\
\text { de camping, estrutura metálica } \\
\text { e bambu }\end{array}$ & 0 & 0 & 0 & 0 & 0 & 1 & 0 & 0 & 0 & 0 & 0 & 1 \\
\hline $\begin{array}{l}\text { Madeira beneficiada, barraca } \\
\text { e bambu }\end{array}$ & 0 & 0 & 0 & 0 & 0 & 2 & 0 & 0 & 0 & 0 & 0 & 2 \\
\hline $\begin{array}{l}\text { Madeira beneficiada, nativa e } \\
\text { bambu }\end{array}$ & 0 & 0 & 0 & 0 & 0 & 0 & 0 & 0 & 0 & 1 & 0 & 1 \\
\hline $\begin{array}{l}\text { Madeira beneficiada, nativa e } \\
\text { barraca de camping }\end{array}$ & 0 & 0 & 0 & 0 & 0 & 0 & 2 & 0 & 0 & 0 & 0 & 2 \\
\hline Madeita nativa & 0 & 1 & 1 & 1 & 8 & 7 & 7 & 6 & 5 & 8 & 13 & 57 \\
\hline Madeira nativa e bambu & 0 & 0 & 0 & 0 & 0 & 3 & 3 & 2 & 0 & 3 & 1 & 12 \\
\hline Madeira nativa e barraca & 0 & 0 & 0 & 0 & 0 & 1 & 1 & 0 & 0 & 1 & 0 & 3 \\
\hline $\begin{array}{l}\text { Madeira nativa, barraca e } \\
\text { camping e estrutura metálica }\end{array}$ & 0 & 0 & 0 & 0 & 0 & 1 & 0 & 0 & 0 & 0 & 0 & 1 \\
\hline PVC & 0 & 0 & 0 & 0 & 0 & 0 & 0 & 0 & 0 & 0 & 1 & 1 \\
\hline Rancho & 5 & 2 & 27 & 31 & 0 & 0 & 0 & 0 & 0 & 0 & 0 & 65 \\
\hline Rancho e barraca de camping & 62 & 8 & 0 & 14 & 0 & 0 & 0 & 0 & 0 & 0 & 0 & 84 \\
\hline Outros & 0 & 0 & 4 & 0 & 0 & 0 & 0 & 0 & 13 & 11 & 8 & 36 \\
\hline Total & 73 & 19 & 51 & 127 & 175 & 176 & 218 & 178 & 217 & 236 & 226 & 1696 \\
\hline
\end{tabular}

Nota: Outros $=$ resposta inexata. 
Tabela 6 - Classificação das respostas referentes ao material utilizado na estrutura dos acampamentos, de acordo com o índice de Constância (C).

\begin{tabular}{|c|c|c|c|c|c|c|}
\hline Estrututa & C1(\%) & Classificação & C2(\%) & Classificação & C3(\%) & Classificação \\
\hline Bambu & 33,33 & B & 87,5 & A & 72,72 & A \\
\hline Bambu e barraca de camping & 0 & $\mathrm{C}$ & 50 & B & 36,36 & B \\
\hline $\begin{array}{l}\text { Bambu, barracas de camping e } \\
\text { madeira }\end{array}$ & 0 & C & 0 & $\mathrm{C}$ & 12,5 & C \\
\hline Barraca de camping & 100 & A & 100 & A & 100 & A \\
\hline Estrutura metálica & 33,33 & B & 100 & A & 81,81 & A \\
\hline Estrutura metálica e bambu & 0 & C & 62,5 & A & 45,45 & B \\
\hline Estrutura metálica e barraca & 0 & C & 75 & A & 54,54 & A \\
\hline Estrutura metálica e madeira nativa & 0 & C & 25 & B & 18,18 & C \\
\hline $\begin{array}{l}\text { Estrutura metálica, bambu e madeira } \\
\text { nativa }\end{array}$ & 0 & C & 25 & B & 18,18 & C \\
\hline $\begin{array}{l}\text { Estrutura metálica, bambu e madeira } \\
\text { beneficiada }\end{array}$ & 0 & C & 12,5 & $\mathrm{C}$ & 9,09 & C \\
\hline Madeira beneficiada & 66,66 & A & 100 & A & 90,9 & A \\
\hline Madeira beneficiada e bambu & 0 & $\mathrm{C}$ & 62,5 & A & 45,45 & B \\
\hline $\begin{array}{l}\text { Madeira beneficiada e barraca de } \\
\text { camping }\end{array}$ & 0 & C & 75 & A & 36,36 & A \\
\hline $\begin{array}{l}\text { Madeira beneficiada e estrutura } \\
\text { metálica }\end{array}$ & 0 & C & 75 & A & 9,09 & A \\
\hline Madeira beneficiada e natica & 0 & C & 62,5 & A & 9,09 & B \\
\hline $\begin{array}{l}\text { Madeira beneficiada, barraca de } \\
\text { camping e estrutura metálica }\end{array}$ & 0 & C & 50 & B & 9,09 & B \\
\hline $\begin{array}{l}\text { Madeira beneficiada, barraca de } \\
\text { camping, estrutura metálica e bambu }\end{array}$ & 0 & C & 12,5 & C & 9,09 & C \\
\hline Madeira beneficiada, barraca e bambu & 0 & $\mathrm{C}$ & 12,5 & $\mathrm{C}$ & 9,09 & $\mathrm{C}$ \\
\hline Madeira beneficiada, nativa e bambu & 0 & C & 12,5 & C & 9,09 & C \\
\hline $\begin{array}{l}\text { Madeira beneficiada, nativa e barraca } \\
\text { de camping }\end{array}$ & 0 & C & 12,5 & C & 9,09 & C \\
\hline Madeita nativa & 66,66 & A & 100 & A & 90,9 & A \\
\hline Madeira nativa e bambu & 0 & C & 62,5 & A & 45,45 & B \\
\hline Madeira nativa e barraca & 0 & $\mathrm{C}$ & 37,5 & B & 27,27 & B \\
\hline $\begin{array}{l}\text { Madeira nativa, barraca e camping e } \\
\text { estrutura metálica }\end{array}$ & 0 & C & 12,5 & C & 9,09 & C \\
\hline PVC & 0 & C & 12,5 & C & 9,09 & $\mathrm{C}$ \\
\hline Rancho & 10 & A & 12,5 & $\mathrm{C}$ & 36,36 & B \\
\hline Rancho e barraca de camping & 66,66 & A & 12,5 & C & 27,27 & B \\
\hline Outros & 33,33 & B & 0 & C & 9,09 & C \\
\hline Total & 33,33 & B & 37,5 & B & 36,36 & B \\
\hline
\end{tabular}

Nota: A) resposta constante; $\mathrm{B}$ ) esporádica; C) rara; $\mathrm{C} 1$ ) antes das normas de convivência; $\mathrm{C} 2$ ) depois das normas; e C3) ao longo dos 11 anos de projeto avaliados. 


\section{Certificação dos acampamentos em adequação às normas de convivência com o rio Araguaia}

Para receber o Certificado de Parceiro Ambiental do NEA/RAN, um acampamento precisa passar por avaliação quanto ao cumprimento ou não das normas de convivência com o rio. As condições para o recebimento do certificado constam nas próprias normas de convivência.

Um acampamento recebe certificação se estiver em conformidade com as normas acordadas, sendo renovada ou não, anualmente. $\mathrm{O}$ objetivo da certificação é reforçar o comportamento ambientalmente adequado o que confere maior prestígio ao acampamento, sendo, por isso, muito valorizado pelos responsáveis de acampamentos. Pressupõe-se que, quanto mais acampamentos cumprirem as normas de convivência com o rio, menor será o impacto ambiental causado pelo turismo de massa na região.

Onúmerodecertificaçõesdosacampamentos vem aumentando a cada fase de avaliação (Tabela 7 e Figura 3). Verificou-se que, na primeira fase, apenas 12 acampamentos foram certificados (1\%); na segunda fase, houve a certificação de 376 acampamentos (35\%); e, na terceira fase, 701 acampamentos alcançaram certificação (64\%), tendo estes cumprido integralmente as normas de convivência com o rio Araguaia, mesmo se levando em conta que o critério de seleção foi muito mais rigoroso na terceira (15 normas) do que na segunda etapa (7 normas).

O aumento do número de certificações dos acampamentos, ao longo dos períodos considerados, demonstra que o trabalho de educação ambiental desenvolvido pelo NEA/ RAN tem contribuído para a adoção, pelos turistas e ribeirinhos, de hábitos ambientais mais saudáveis e na melhoria do estado de conservação desse ecossistema, observandose uma tendência à diminuição das atividades impactantes ao longo dos anos.

O cadastramento de cada acampamento, o georreferenciamento, o trabalho integrado com a fiscalização, o monitoramento $e$ orientação sobre a melhor forma de uso e ocupação, a sensibilização através das reuniões e dinâmicas nos acampamentos colaboraram para a diminuição do principal impacto ambiental da região: o lixo deixado nas praias. Este, além da evidente degradação ambiental, segundo a equipe do NEA/RAN e do PQA/GO, diminuía a qualidade dos ambientes de desova da tartaruga-da-amazônia ( $P$. expansa), severamente prejudicada em praias poluídas, refletindo negativamente na população desses quelônios.

Tabela 7-Evolução das porcentagens de acampamentos certificados.

\begin{tabular}{|l|l|l|l|l|}
\hline \multicolumn{1}{|c|}{ Localização } & $\mathbf{1}^{\mathbf{a}}$ fase & $\mathbf{2}^{\mathbf{a}}$ fase & $\mathbf{3}^{\mathbf{a}}$ fase & \multicolumn{1}{|c|}{ Total } \\
\hline Aruanã & $\ldots \ldots$ & 12 & 326 & 338 \\
\hline Bandeirantes & 0 & 33 & 90 & 123 \\
\hline Cocalinho & $\ldots \ldots$ & 2 & 87 & 89 \\
\hline Luis Alves & 4 & 256 & 140 & 400 \\
\hline $\begin{array}{l}\text { Ponta Sul da Ilha do } \\
\text { Bananal }\end{array}$ & 8 & 73 & 58 & 139 \\
\hline Total & 12 & 376 & 701 & 1089 \\
\hline Percentil & 1,00 & 35,00 & 64,00 & 100,00 \\
\hline
\end{tabular}

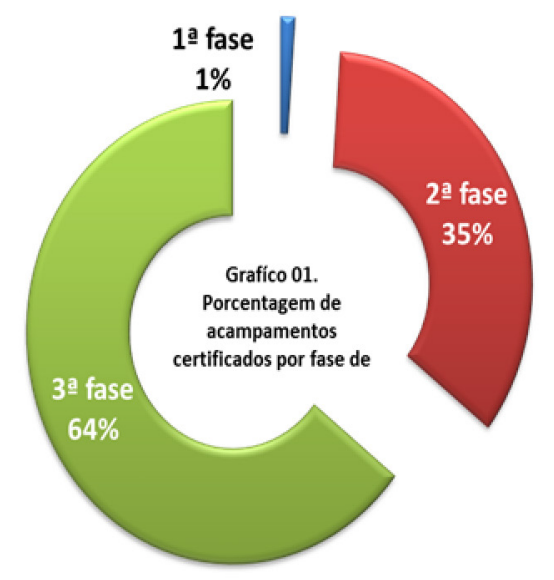

Figura 3 - Acampamentos com a Certificação de Parceiro Ambiental do NEA/RAN, em adequação às Normas de Convivência com o Rio Araguaia.

O turismo tem o potencial de trabalhar de maneira harmônica a utilização do meio ambiente, pois uma de suas modalidades, o ecoturismo, utiliza, de forma sustentável, o patrimônio natural e cultural, incentivando a conservação $e$ formação de uma cConsciência ambientalista, promovendo o bem-estar das populações envolvidas. Portanto, o turismo deve ser desenvolvido de forma que não só a intervenção antrópica minimize impactos, como também os ecossistemas sejam capazes de absorvê-los sem maiores danos (Galinkin, 2003).

Contudo, apesar dos esforços e resultados consideráveis do projeto de ordenamento do turismo na região do Araguaia, rapidamente avaliado nesta abordagem, a intensa, histórica e sistemática exploração turística das matas ciliares, 
lagos marginais, praias e recursos faunísticos nas demais regiões não cobertas por este ou por outros projetos análogos, permite supor que esse grande rio vem sendo prejudicado devido à ocupação, mesmo que temporária, incorreta e desordenada de suas margens, e exploração dos seus recursos. Isso se evidencia na medida em que, relativamente, poucos turistas têm a percepção das alterações ambientais causadas pela prática desse lazer da forma como tem sido generalizadamente praticada, notadamente no seguimento ecoturístico, que aumenta em proporção descompassada do alcance das efetivas ações do complexo processo de sensibilização ambiental (Carvalho, 2006; Lacava \& Balestra, 2019).

A relevância de um projeto de educação ambiental voltado para uma iniciativa singular em ordenar uma atividade turística de larga escala, historicamente desarmônica com o meio ambiente e de grande complexidade operacional, talvez pioneira no Brasil, que se esforçou para se efetivar em mais de duas décadas de atuação, teve, entre vários importantes fatores motivadores, o desafio de protagonizar medidas em prol da conservação dos recursos naturais, especialmente dos ambientes de reprodução de espécies de quelônios amazônicos, que competem com os de interesse maior do turismo regional, as praias de nidificação dessas espécies que ainda sofrem com a intensa exploração pelo consumo local e mercados ilegais.

Ressalta-se que o equilibrio populacional dessas espécies é dificultado em razão do ciclo de vida longo, em que a maturidade sexual é atingida tardiamente, resultando em baixa taxa de substituição de indivíduos na população (Vogt, 2008; Balestra, 2016; Balestra \& Lacava, 2016). Por conta disso, a manutenção de populações naturais saudáveis depende da existência de uma quantidadeviáveldeanimaissexualmentemaduros, principalmente de fêmeas adultas reprodutoras, que são as mais caçadas por possuírem maior tamanho corporal e maior susceptibilidade à apanha durante a desova, época que, infelizmente, coincide com a prática do campismo à beira-rio em muitas localidades nas regióes no centro-oeste a norte do país. Embora a captura de adultos e a coleta de ovos de quelônios sejam proibidas pela legislação brasileira, essa é uma prática comum na Amazônia ainda nos dias de hoje. Além da intensa predação de indivíduos adultos, em muitos locais não protegidos ou sem nenhum ordenamento de uso pode haver até $100 \%$ de predação dos ovos desses animais (Vogt, 2008; Balestra, 2016; Balestra \& Lacava, 2016; Lacava \& Balestra, 2019).

\section{Conclusão}

O distrito de Luís Alves, situado no noroeste de Goiás, foi a localidade mais procurada pelos turistas nas temporadas de praias na região do médio Araguaia, provavelmente por ser considerada uma região de grande potencial ecoturístico, pois as praias ficam próximas à cidade, que possui infraestrutura razoável.

Os dados obtidos no presente estudo corroboram os relatos sobre a tradição do povo goiano de acampar nas praias do rio Araguaia, no período das férias escolares de julho, pois a maioria dos responsáveis pelos acampamentos é procedente de cidades goianas.

Diante dos resultados, foi possível constatar que houve mudança comportamental positiva dos campistas em relação ao meio ambiente, destacando-se o que diz respeito ao destino do lixo; no entanto, na escolha do material usado na estrutura dos acampamentos, a utilização de madeira nativa se manteve relativamente constante, comparando-se as períodos avaliados antes e após a vigência das Normas de Convivência com o Rio Araguaia, muito embora a utilização de madeira nativa sempre tenha se mostrado comparativamente pequena em relação às outras opções para esse fim. Essa mudança deve-se, especialmente, ao trabalho realizado pelo NEA/RAN, que monitorou, informou e estabeleceu um processo educativo para sensibilização ambiental junto aos frequentadores das praias do rio Araguaia.

Para sensibilizar e melhor informar os turistas quanto às regras de boa convivência com o meio ambiente, é imprescindível a continuidade do trabalho de educação ambiental na região, pois os resultados já alcançados, indicam fortemente que essa atuação gerou mudanças positivas no comportamento dessas pessoas em relação à natureza, favorecendo a conservação dos recursos naturais. 


\section{Agradecimentos}

Ao PIBIC/ICMBio, pelo suporte financeiro através da concessão da bolsa de apoio à pesquisa que viabilizou a realização deste trabalho. Ao RAN, pela proposição e supervisão deste trabalho, em especial ao seu extinto Núcleo de Educação Ambiental (NEA), que sempre contou com o aguerrido, apaixonado e competente empenho dos seus responsáveis, em especial Nilza Silva Barbosa, Luís Alfredo Costa Freitas, Antônio Alencar Sampaio e Glaura Cardoso Soares, aos quais dedicamos este trabalho.

\section{Referências}

Agetur. Agência Goiana de Turismo, 2005. Disponível em http://www.agetur.go.gov.br/municipio. Acesso em: 18/10/2020.

Balestra RAM (org.). Manejo conservacionista e monitoramento populacional de quelônios amazônicos. 1 ed. Ibama. 2016. 137p.

Balestra RAM \& Lacava RV (orgs.). Roteiro para inventários e monitoramentos de quelônios continentais. Biodiversidade Brasileira. 6: 114-152, 2016.

Barbosa AS. A história de um velho com feições juvenis pedindo socorro, 2008. Disponível em http://www. agsolve.com.br. Acesso em: 10/12/2012.

Borges VC. A biodiversidade do cerrado brasileiro; os(as) raizeiros(as) de Goiás/GO, 2010. Disponível em: http://www.geo.ufv.br/simposio/simposio/trabalhos/ comunicacao_coordenada/012.pdf. Acesso em: 15/12/2012.

Carvalho AR, Ângelo PG, Melo ME. Estudo do perfil socioeconômico e percepção ecológica do turista do Rio Araguaia, região de Aruanã, Goiás, Brasil. 2006. Disponível em https://www.seb-ecologia.org.br/revistas/ indexar/anais/viiceb/resumos/818a.pdf. Acesso em 12/01/2013.

Freitas LAC. 2008. Auditoria ambiental de certificação de acampamento. Trabalho de Conclusão de Curso (MBA em Perícia, Auditoria e Gestão Ambiental. Faculdade Oswaldo Cruz. 150p.

Galinkin, M. 2003. Estado Ambiental de Goiás 2002 GEOGOIÁS. Ed. Goiânia. 272p.

Ibama. Instituto Brasileiro do Meio Ambiente e dos Recursos Naturais Renováveis. 2005. Relatório do projeto parcerias de ordenamento do turismo $e$ ecoturismo no rio Araguaia. Ibama. 67p.
Ibama. Instituto Brasileiro do Meio Ambiente e dos Recursos Naturais Renováveis. 1997. Rio Araguaia: a temporada da consciência. Ibama. 28p.

Ibama. Coleção Meio Ambiente: Uma experiência de Educação Ambiental no rio Araguaia. 2004. 17p.

Ibama. Projeto Parcerias de Ordenamento do turismo e ecoturismo no rio Araguaia. Goiânia, GO: 2002.

Lacava RV \& Balestra RAM (orgs.). 2019. Plano de Ação Nacional para a Conservação dos Quelônios Amazônicos. Ibama. 279p.

Latrubesse EM \& Stevaux JC. Geomorphology and Environmental Aspects of Araguaia Fluvial Basin, Brazil. Z. Geomorphologie, v. 129, p. 109, 2002.

Mendonça RA. 2005. Experiência na natureza segundo Joseph Cornell, p. 135-154. In: Serrano, C. (org.) A educação pelas pedras: ecoturismo e educação ambiental. Chronos.

Myers N, Mittermeier R, Mittermeier C. Biodiversity hotspots for conservation priorities. Nature 403, 853858 (2000). https://doi.org/10.1038/35002501.

Ratter JA, Ribeiro JF. \& Bridgwater. The brazilian cerrado vegetation and threats to its biodiversity. Annals of Botany 80: 223-230, 1997.

Serrano C, Luchiari MT. 2005. (Eco)turismo e meio ambiente no Brasil: territorialidades e contradições, $\mathrm{p}$. 505-515. In: Trigo, L. G. G. (edit.) Análises regionais e globais do turismo brasileiro. Roca.

Soares VCN. 2005. Estudo da Comunidade de Anuros (AMPHIBIA) da Sub-região do Baixo Rio Madeira, no Estado de Rondônia. Trabalho de conclusão de curso (graduação em ciências biológicas). Faculdade da Terra de Brasília. 87p.

Vogt RC. 2008. Tartarugas da Amazônia. Gráfica Biblos. 104p.

Zwicker, Ronaldo. Introdução ao banco de dados: Microsoft Access. 1998. Disponível em: http://www2. dc.uel.br/ rafael/ie/cop059/Microsoft\%20Access.pdf. Acesso em: 12/01/2013. 


\section{Anexo}

\section{Normas de Convivência com o Rio Araguaia}

1. Na instalação de acampamentos não use recursos vegetais da região. Use estrutura metálica, bambu e madeira beneficiada.

2. Todo o material do acampamento deverá ser retirado no final da temporada, deixando a praia limpa.

3. O lixo deverá ser separado. Enterre o orgânico no barranco longe da margem do rio.

4. O lixo reciclável (plástico, papel, lata, vidro) deverá ser levado de volta para a cidade ou depositado em locais determinados. Nunca o deixe nas margens das rodovias.

5. Na construção de sanitários, use material degradável no escoramento da fossa (balaios, caixotes, trançados de palha, tábuas, bambus etc.). Não é permitido o uso de tambores.

6. É proibida a prática de cimentados nas praias e margens do rio.

7. Não use foguetes e fogos de artifício, pois afugentam os animais e podem provocar incêndios.

8. Instale abafadores nos motores dos geradores a fim de diminuir a poluição sonora e desligue-os sempre que possível.
9. Pesque somente com linha de mão, caniço ou molinete. Não use material predatório. Obedeça a lei de pesca.

10. Caçar é crime. Não mate nem aprisione animais silvestres.

11. Para que o acampamento receba o certificado de parceiro é necessário:

A) cumprir as normas de convivência;

B) participar das reunióes, na praia ou no acampamento;

C) ser avaliado tecnicamente sobre a percepção ambiental no acampamento ou na praia;

D) não ser surpreendido em nenhuma ação predatória; Goiânia.

E) participar da reunião dos acampantes em

12. O acampamento deve ter identificação através de faixas ou placas.

13. Estacionar carros nas praias e som muito alto não combina com o rio Araguaia.

14. As gaivotas gostam de sossego e os seus ninhos são protegidos. Os acampamentos devem se distanciar destas áreas.

15. A visita nos lagos só é permitida para contemplação. Devem ser visitados com cuidado, sem barulho, sem pesca e com muito respeito.

Biodiversidade Brasileira - BioBrasil.

Edição Temática: PIBIC

n. 1,2022

http://www.icmbio.gov.br/revistaeletronica/index.php/BioBR

Biodiversidade Brasileira é uma publicação eletrônica científica do Instituto Chico Mendes de

Conservação da Biodiversidade (ICMBio) que tem como objetivo fomentar a discussão $e$ a disseminação de experiências em conservação e manejo, com foco em unidades de conservação $e$ espécies ameaçadas.

ISSN: 2236-2886 